Article

\title{
Harnessing Wind Energy with Hydrostatic Transmission Coupled to an Electromagnetic Frequency Regulator
}

\author{
Ariel S.L. Patriota ${ }^{1, *}$, Ricardo F. Pinheiro ${ }^{2}$ and Gabriel I. Medina T. ${ }^{3}$ \\ 1 Currently taking the Professional Master in Electrical Energy, Federal University of Rio Grande do Norte, \\ Natal 59078-970, Brazil. \\ 2 Department of Computer Engineering and Automation, Federal University of Rio Grande do Norte, Natal \\ 59078-970, Brazil. E-mail: ricpinh@ufrnet.br. \\ 3 Department of Mechanical Engineering, Federal University of Rio Grande do Norte, Natal 59078-970, Brazil. \\ E-mail: gmedinat@ct.ufrn.br.
}

\begin{abstract}
This work presents an alternative to harnessing wind energy with an Electromagnetic Frequency Regulator (EFR) coupled to a hydrostatic transmission and associated with a horizontal axis wind turbine, a bidirectional frequency inverter and a secondary energy source, in a hybridized system. The hydrostatic transmision is composed by a fixed displacement axial piston pump and a variable displacement, swash plate, axial piston motor. Feedback linearization was used as a technique to control the motor geometric displacement, and a prediction algorithm for the steady state rotations of the armature and the electromagnetic field has been developed. A $5 \mathrm{~kW}$ project was simulated on a Scilab platform, with combinations of constant or variable load, and constant or variable wind speed. The results indicated that the system was able to supply the generator load, adapting to fluctuations in wind speed. The possibility of storing wind energy through the inverter has also been proven. The system can accumulate energy in batteries during the fastest wind regimes, to use it when the turbine power is lower than the load.
\end{abstract}

Keywords: Electomagnetic Frequency Regulator, Hydrostatic transmission, Wind turbines, Feedback linearization, Variable load, Induction machine, Slip.

\section{Introduction}

The operation of wind turbines has already become economically viable in regions with low intensity winds, and the demand for this type of solution has grown worldwide [1,2]. The industry standardized topology employs the horizontal axis turbine [3-5]. In this configuration, the turbine axis is connected to the generator by using: (1) FSWT (fixed speed) systems with gearbox and synchronous or induction generators (squirrel cage) directly connected to the power grid; (2) LVSWT (limited variable speed) systems with gearbox and induction generator with ventilated and coiled rotor directly connected to the power grid; and (3) a VSWT (variable speed) system with synchronous or induction generator, with or without speed multiplier, mediated by AC / DC / AC converters. In all these cases, the functioning of the system depends on the power grid connection.

The application of hydraulic transmissions in wind systems seeks to replace a monolithic system, the gearbox, with a combination of pump and motor (or hydraulic turbine), e.g.: (1) The Delft Offshore Turbine (DOT) uses a hydraulic pump that pressurizes seawater to a manifold placed on a platform [6]. The water reaches the platform with high speed and drives a Pelton wheel that is attached to the generator; (2) Norwegian company ChapDrive has patented [7] a system composed of pump, motor and synchronous generator. A control system ensures constant synchronous speed regardless of wind 
fluctuations [8, p. 1]; and (3) A design by Flesch [9] employs a hydrostatic transmission associated with a PID controller and a synchronous generator (Fig. 2). The author has shown that the transmission acts as a filter, reducing the impact of wind speed variations on the power output.

The Electromagnetic Frequency Regulator (EFR) is a squirrel-cage induction machine in which: (1) The component corresponding to the induction motor stator is supported on bearings and can rotate freely; because it contains the armature windings of the machine, it will be called armature; (2) The armature rotates together with the driving source (a hydraulic motor, in the topology proposed here); (3) The interaction of the EFR rotor with the armature is more complex than that of a conventional motor, with a frequency inverter dynamically adjusting the rotation of the electromagnetic field to the variable rotation of the armature to keep the rotor rotation constant in response to load fluctuations and turbine power. This project pressuposes a bidirectional inverter, providing field rotation in any direction; (4) The power of the inverter comes from a supplementary source (e.g. photovoltaic panels, batteries), which allows to remove power from the battery in periods of low wind activity, or, otherwise, direct the excess wind power to the battery.

This paper proposes a way to extract wind energy using: (1) a hydrostatic transmission instead of the gearbox; (2) the EFR with the frequency inverter isolated from the grid; (3) separate controls for the motor and the inverter; and (4) the generator directly connected to the grid. This text, like the original proposal of the technology [10-13], makes reference to the synchronous generator, but the idea also applies to the induction model [14]. The system (cf. Fig. 1) contains a hydromechanical part (turbine and transmission) and an electromechanical part (EFR, generator and supplementary source).

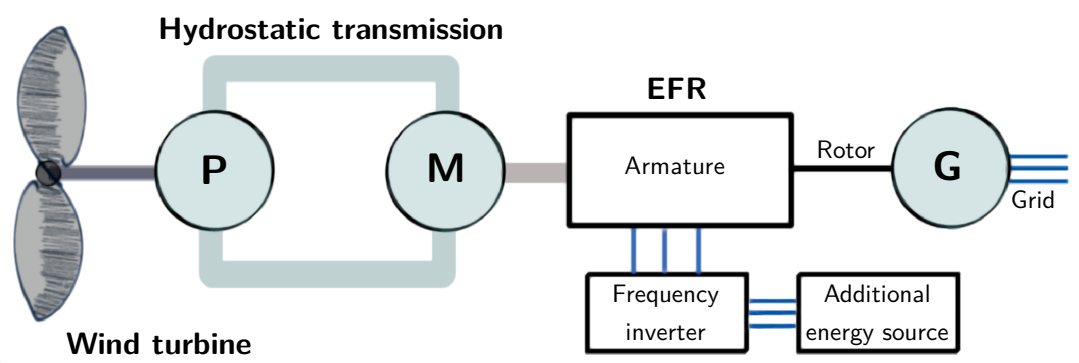

Figure 1. General layout: Turbine-Hydrostatic Transmission-EFR

The transmission consists of a rotary volumetric pump (P) and a hydraulic motor (M) [9, p. 69]. The pump has a fixed displacement (the amount of fluid driven per revolution); the motor displacement is variable. This combination produces a transmission with constant power: by increasing the motor displacement, the armature rotation decreases, but the torque increases, so that the product of the two is constant and equals the pump hydraulic power.

This work will prepare the basic design of an energy system according to the scheme of Fig. 1 and simulate its response (in Scilab) for a range of speeds and powers of interest. The fundamental design parameters are: (1) the system must deliver $5 \mathrm{~kW}$ of mechanical power to the generator input; and (2) the reference speed for the wind is $7 \mathrm{~m} / \mathrm{s}$. The power regulation for the turbine will be done through a pitch control system (not covered here).

\section{The Hydrostatic Transmission}

Figure 2 shows a system composed of a pump $(\mathrm{P})$ mechanically connected to a wind turbine and a hydraulic motor $(\mathrm{M})$ mechanically connected to the EFR armature. The circuit is closed, because the fluid circulates between the pump and the turbine without intermediation of a reservoir (R). An auxiliary pump (AP) is driven by an electric motor (EM) to replenish the fluid lost by leakage and normalize the pressure by using the stock in the reservoir. In an open circuit, the fluid would pass through the reservoir after leaving the motor. Filters clean the fluid and valves protect the circuit against overpressure (relief valves) or inversion of the flow direction (check valves). The circuit 
configuration is in closed loop, because of the feedback: the tachometer and the pressure transducer send signals to the controller to interfere with the displacement of the hydraulic motor, changing its rotation.

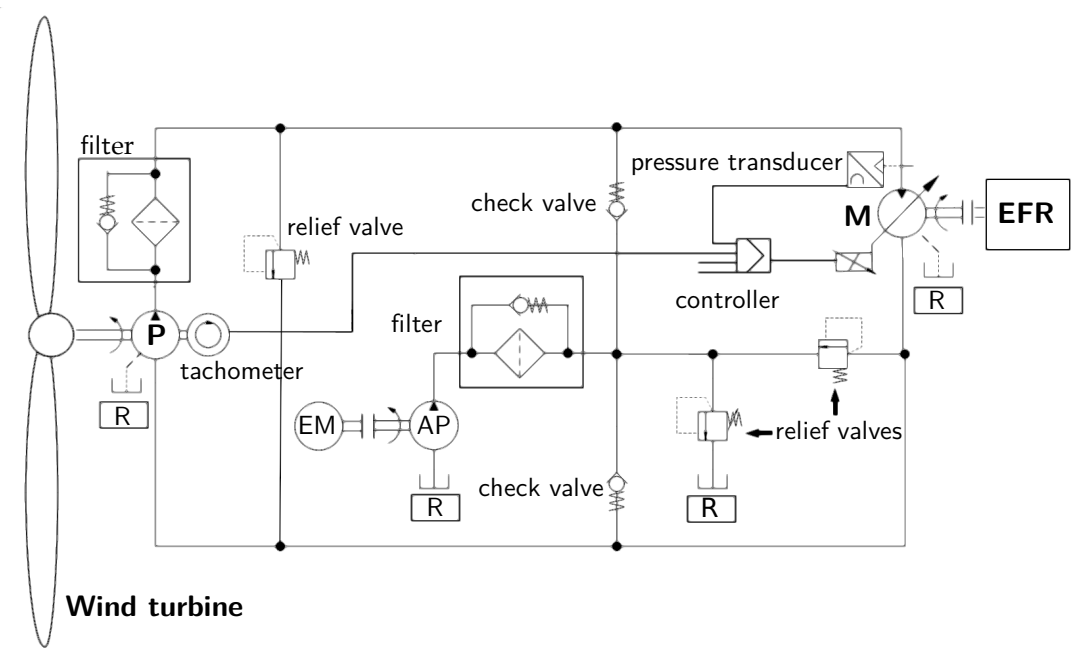

Figure 2. Hydrostatic transmission between wind turbine and the Eletromagnetic Frequency Generator. Closed circuit with feedback. Adapted from [9, p. 91]

The general recommendation as to which pump and motor class to use is to adopt an axial piston pump and an axial piston motor, due to their high efficiency [9, p. 86]. Because of the speed multiplication, the pump will operate with low speed and high displacement, and the motor, with high speed and low displacement. In this case, if the generator has a large pole pair number, the motor can operate at a lower speed and at a higher displacement. It is possible to choose, for the transmission topology, a closed or open circuit configuration; the last option, which is simpler, will be adopted here. Besides, as the system is of low power, the pressure level will be $\Delta p_{\text {nom }}=200$ bar, a relatively low value.

Walking through the chain: EFR $\rightarrow$ motor $\rightarrow$ pump $\rightarrow$ turbine, one can determine the power flow and process the inefficiencies by an energy balance. In this regard, it is convenient to define two kinds of efficiency: volumetric, $\eta^{v}$ (with respect to flow), and mechanical, $\eta^{m}$ (with respect to torque). The total efficiency $\eta$ is given by the product $\eta^{v} \eta^{m}$.

The power flow comes next:

$$
\begin{aligned}
P_{\mathrm{P}}^{\text {in }} & =P_{t} \\
P_{\mathrm{P}}^{\text {out }} & =\eta_{\mathrm{P}} P_{\mathrm{P}}^{\text {in }} \\
P_{\mathrm{M}}^{\text {in }} & =P_{\mathrm{P}}^{\text {out }} \\
P_{\mathrm{M}}^{\text {out }} & =\eta_{\mathrm{M}} P_{\mathrm{M}}^{\text {in }} \\
P_{a} & =P_{\mathrm{M}}^{\text {out }}
\end{aligned}
$$

and the power delivered to the armature is: $P_{a}=\eta_{\mathrm{M}} \eta_{\mathrm{P}} P_{t}$.

\subsection{Torques and Flow Rates}

The hydraulic power $P_{h}$ is given by the product of the flow rate by the differential pressure: $P_{h}=Q \Delta p$. For the pump, the flow rate is the outgoing:

$$
Q_{\mathrm{P}}=d_{\mathrm{P}} \omega_{t} \eta_{\mathrm{P}}^{v}
$$

where $d_{\mathrm{P}}$ is the volumetric displacement of the pump and $\omega_{t}$ is the turbine rotation. Replacing (6) in the hydraulic power expression and comparing with $P_{h}=\eta_{\mathrm{P}} T_{t} \omega_{t}$ gives $\Delta p=\eta_{\mathrm{P}}^{m} T_{t} / d_{\mathrm{P}}$. 
For the motor, the flow rate is that of input - this definition is similar to the former, but with the efficiency in the denominator:

$$
Q_{\mathrm{M}}=\frac{d_{\mathrm{M}} \omega_{a}}{\eta_{\mathrm{M}}^{v}}
$$

The motor delivers a torque

$$
T_{\mathrm{M}}=\frac{\eta_{\mathrm{M}} P_{h}}{\omega_{a}}=\eta_{\mathrm{M}}^{m} d_{\mathrm{M}} \Delta p
$$

Assuming no leakage in the line, it follows that: $d_{\mathrm{P}} \omega_{t} \eta_{\mathrm{P}}^{v}=d_{\mathrm{M}} \omega_{a} / \eta_{\mathrm{M}^{\prime}}^{v}$, which results in the transformation ratio

$$
\frac{\omega_{a}}{\omega_{t}}=\eta_{\mathrm{P}}^{v} \eta_{\mathrm{M}}^{v} \frac{d_{\mathrm{P}}}{d_{\mathrm{M}}}
$$

Let (9) be compared with the classic gear identity: $\omega_{a}=e \omega_{t}$, where $e$ is given by

$$
e=\frac{\prod \text { driving teeth }}{\prod \text { driven teeth }}
$$

The pump is the driving element, and the motor is the driven element. Thus, the hydrostatic transmission is equivalent to a gearbox whose drive gear has a tooth number given by $d_{\mathrm{P}} \eta_{\mathrm{P}}^{v}$ and the driven gear has its tooth number given by $d_{\mathrm{M}} / \eta_{\mathrm{M}}^{v}$. The ratio $\omega_{a} / \omega_{t}$ can be changed dynamically. The torque transformation ratio is given by: $T_{a}=\eta_{\mathrm{P}}^{m} \eta_{\mathrm{M}}^{m}\left(d_{\mathrm{M}} / d_{\mathrm{P}}\right) T_{t}$.

\subsection{The Turbine}

The turbine wind power depends on: the density $\rho$ of the air, the area $A$ swept by the blades, the wind speed $u_{\infty}$ and a power coefficient $C_{P}[2,4,5,15]$ :

$$
P_{t}=\frac{1}{2} \rho C_{P} A u_{\infty}^{3}
$$

The wind speed is related to the turbine speed by the specific speed

$$
\lambda=\frac{\omega_{t} R}{u_{\infty}}
$$

\section{The Electromagnetic Frequency Regulator - EFR}

Let $T_{a}$ be the torque applied by the motor on the EFR armature; $T_{e}$, the electromagnetic torque transmitted to the EFR rotor through the air gap; and $T_{r}$, the load resistant torque. The rotational inertias of the EFR armature and rotor are $J_{a}$ and $J_{r}{ }^{1}$ The angular velocities involved are: (1) $\omega_{a}$, the absolute rotation of the armature; (2) $\omega_{i}$, the rotation of the electromagnetic field produced by the inverter and generated in the armature windings;, ${ }^{2}$ (3) $\omega_{e}=\omega_{a}+\omega_{i}$, the absolute rotation of the electromagnetic field; and (4) $\omega_{r}$, the absolute rotation of the rotor. Fig. 3 shows a dynamic arrangement of the main EFR components along with the speeds.

1 The armature inertia is the mass moment of inertia of the set consisting of the armature and its driving element (in this case, the hydraulic motor), and the rotor inertia is the mass moment of inertia of the set consisting of the rotor and its driven element (in this case, the synchronous generator rotor).

2 This text considers the mechanical rotation of the field, that is, it defines $\omega_{i}=\omega_{i}^{\text {ele }} / \mathrm{pp}$, where pp is the EFR pole pair number, $\omega_{i}^{\text {ele }}=2 \pi f$ and $f$ is the grid electrical frequency. 


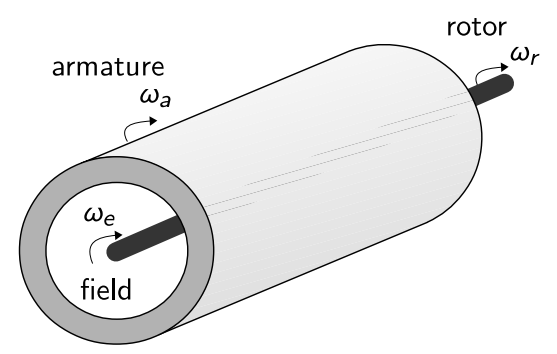

Figure 3. Absolute angular speeds of EFR components

In order to measure slip as simply as possible, a frame must be fixed on the armature, where the rotating field is generated. The synchronous rotation measured there will be $\omega_{e}-\omega_{a}=\omega_{i}$, and the rotor speed will be $\omega_{r}-\omega_{a}$. The rotor internal slip is defined as

$$
s=\frac{\left(\omega_{e}-\omega_{a}\right)-\left(\omega_{r}-\omega_{a}\right)}{\omega_{e}-\omega_{a}}=\frac{\omega_{a}+\omega_{i}-\omega_{r}}{\omega_{i}}
$$

The conventional, external or apparent slip, seen by an observer on Earth, is

$$
s_{0}=\frac{\omega_{a}+\omega_{i}-\omega_{r}}{\omega_{a}+\omega_{i}}
$$

which results in: $s=s_{0}\left(1+\omega_{a} / \omega_{i}\right)$. Then, $\omega_{a}=0$ implies $s=s_{0}$ (conventional induction machine).

The dynamic equations for the rotor and the armature are:

$$
\begin{aligned}
J_{a} \dot{\omega}_{a} & =T_{a}-T_{e}-T_{f a} \\
J_{r} \dot{\omega}_{r} & =T_{e}-T_{r}-T_{f r}
\end{aligned}
$$

where the friction torques $T_{f}$ are modeled in the form $\left.T_{f}=\right\rfloor \omega\lceil B \omega$, where $B$ is a friction coefficient and the operator $\rfloor \cdot\left\lceil\right.$ indicates the signum function. Solving the equations for $T_{a}$ and $T_{e}$ gives:

$$
\begin{aligned}
& T_{a}=T_{r}+J_{r} \dot{\omega}_{r}+J_{a} \dot{\omega}_{a}+T_{f a}+T_{f r} \\
& T_{e}=\frac{T_{r}+T_{a}+J_{r} \dot{\omega}_{r}-J_{a} \dot{\omega}_{a}+T_{f r}-T_{f a}}{2}
\end{aligned}
$$

In steady state, $T_{a}=T_{r}+T_{f a}+T_{f r}$ and $T_{e}=T_{r}+T_{f r}$. With no friction, it simplifies to: $T_{a}=T_{e}=T_{r}$.

\subsection{Powers and Rotations}

The rotor power is the sum of the mechanical power delivered to the armature plus the mechanical power due to the rotating field produced by the armature currents, minus the friction losses: ${ }^{3}$

$$
T_{a} \omega_{a}+(1-s) P_{i}-\left(T_{f a} \omega_{a}+T_{f r} \omega_{r}\right)=T_{r} \omega_{r}
$$

Grouping the above terms in $\omega_{a}$ and $\omega_{r}$, replacing $T_{a}-T_{f a}=T_{r}+T_{f r}$, dividing by $T_{a} \omega_{a}$ and simplifying gives:

$$
\frac{P_{i}}{P_{a}}=\frac{\omega_{i}}{\omega_{a}}\left(1-\frac{T_{f a}}{T_{a}}\right)
$$

3 The formulation by Ramos et al. [14] uses the conventional slip: $\left(1-s_{0}\right)\left(P_{a}+P_{i}\right)=P_{r}+$ losses. By rewriting $s_{0}$ as a function of $s$, one can arrive at (19). 
Solving the gap torque equation (18) for $\dot{\omega}_{r}$ gives the rotor equation:

$$
\dot{\omega}_{r}=\frac{2 T_{e}+J_{a} \dot{\omega}_{a}-\sum T}{J_{r}}
$$

where $\sum T=T_{a}+T_{r}-T_{f a}+T_{f r}$. This first-order differential equation is non-linear and autonomous (the variable time does not appear explicitly). From (21) comes the following dynamic problem: what should the field and armature rotation values be to keep the rotor angular speed constant and at the level required by the generator? This is a matter of control, the subject of the next section.

\subsection{Control through Feedback Linearization}

Be the first-order differential equation $\dot{y}=f+g u$, where $y$ is a variable to be controlled, $f$ and $g$ are continuous functions (not necessarily linear) and $u$ is a signal described by a control law to be implemented in some iterative routine [16]. The first approximation to $u$ will determine a first approximation to $y$, the result serving as basis for the next calculation, which generates a feedback cycle that (due to the continuity of $f$ and $g$ ) ensures the convergence of $y$ to the desired signal $y^{*}$. One writes $y^{*}$ to distinguish it from the actual value $y$. The difference between these quantities is the error $\epsilon=y-y^{*}$. The purpose of the control is to make $y \rightarrow y^{*}$ as $t \rightarrow \infty$, so the following control law is proposed:

$$
u=\frac{-f+\dot{y}^{*}-\kappa \epsilon}{g}
$$

where $\kappa>0$. This law, once implemented in the expression of $\dot{y}$, gives $y=\dot{y}^{*}-\kappa \epsilon$. But $\dot{y}-\dot{y}^{*}=$ $\dot{\epsilon} \Longrightarrow \dot{\epsilon}+\kappa \epsilon=0$, which is a linear ODE, whose solution follows the form $\epsilon=\epsilon_{0} \mathrm{e}^{-\kappa t}$. Therefore, the strategy of formulating $u$ in terms of (22) cancels the original nonlinearities and produces a series $[y] \rightarrow y^{*}$. Then, a nonlinear output problem became a linear error problem. [16, p. 527].

The mere numerical integration of $f+g u$, without analyzing the behavior of $f$ and $g$, can lead to inadequate solutions. If, for example, a law be written for the angular acceleration of the field, it is necessary to put $\dot{\omega}_{a}$ as a function of $\dot{\omega}_{i}$ in (21):

$$
\dot{\omega}_{r}=\frac{\sum T-2 T_{e}-J_{a} \dot{s} \omega_{i}+J_{a}(1-s) \dot{\omega}_{i}}{J_{a}-J_{r}}
$$

This equality, written in the form $f+g u$, generates the following identities: $u=\dot{\omega}_{i}, g=$ $J_{a}(1-s) /\left(J_{a}-J_{r}\right)$ and $f=\left(\sum T-2 T_{e}-J_{a} \dot{s} \omega_{i}\right) /\left(J_{a}-J_{r}\right)$. The control law for $\dot{\omega}_{i}$ according to (22) is

$$
u=\dot{\omega}_{i}=\frac{2 T_{e}-\sum T+J_{a} \dot{s} \omega_{i}-\left(J_{a}-J_{r}\right) \kappa\left(\omega_{r}-\omega_{r}^{*}\right)}{J_{a}(1-s)}
$$

The graphs of Figs. $4 \mathrm{a}-4 \mathrm{~b}$ show a simulation of start and operation of the EFR modeled with the law of (24), and they have two adverse effects: (1) the oscillation of $\omega_{i}, T_{e}$ and $s$ disguised by a smooth rotation of the rotor; and (2) the slip stabilization at a level much higher than expected. Since, in an induction machine, the torque-slip characteristic leads to same electromagnetic torque can be produced in two different slips for the same value of $\omega_{i}$, the situation corresponds to an unstable equilibrium. The controller was not able to accelerate the field due to counting $\omega_{r}-\omega_{r}^{*}=0$ in (24), just trying to keep $\omega_{i}$ in this wrong "solution". Therefore, the feedback linearization applied to $\omega_{i}$ in terms of the approximation $\omega_{r}-\omega_{r}^{*}$ is not suitable for the simulation. However, once the EFR has two independent energy inputs (the hydraulic motor and the frequency inverter), there is room to implement separate controls for (1) the motor displacement and (2) the field rotation. As it will be seen below, the feedback linearization got successful in the first case; for the second, a procedure will be developed to produce convergence regardless of feedback. 


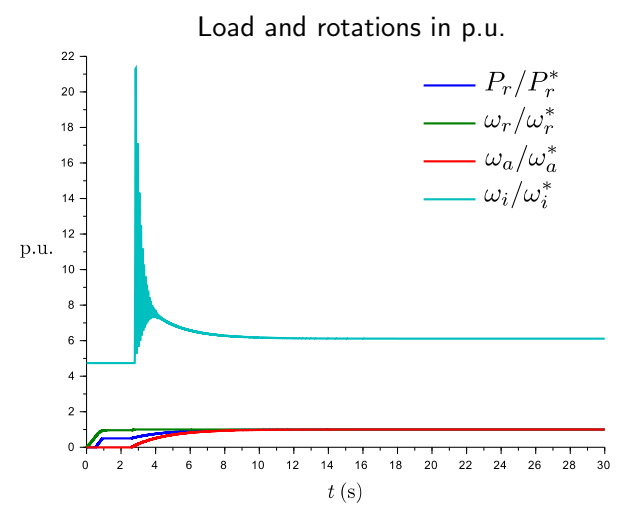

(a) Wrong prediction for $\omega_{i}$

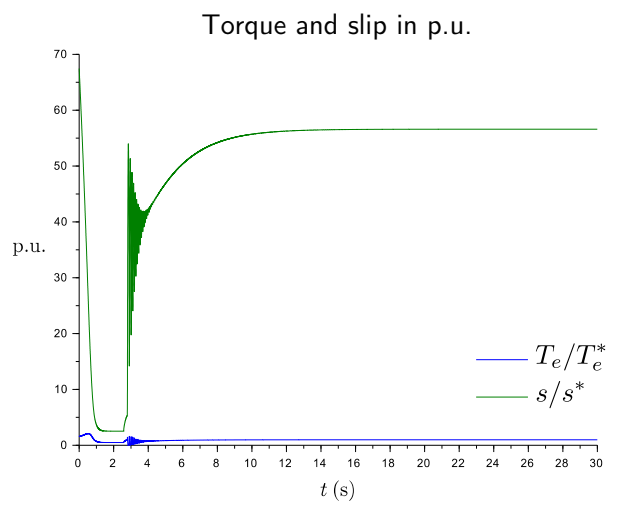

(b) Slip of the unstable solution

Figure 4. Ill-posed EFR simulation with control law written for field acceleration in terms of error in rotor speed

\subsubsection{Control of the Hydraulic Motor Displacement}

Replacing the result of (8) in (15) and solving for $\dot{\omega}_{a}$ gives:

$$
\dot{\omega}_{a}=\frac{\eta_{\mathrm{M}}^{m} d_{\mathrm{M}} \Delta p-T_{e}-B_{a} \omega_{a}}{J_{a}}
$$

Putting (25) in the form $f+g u$ gives the identities: $u=\eta_{\mathrm{M}}^{m} d_{\mathrm{M}}, g=\Delta p / J_{a}$ and $f=-\left(T_{e}+B_{a} \omega_{a}\right) / J_{a}$. Based on the above parameters, the control law for the displacement follows:

$$
d_{\mathrm{M}}=\frac{T_{e}+B_{a} \omega_{a}-J_{a} \kappa_{\mathrm{M}}\left(\omega_{a}-\omega_{a}^{*}\right)}{\eta_{\mathrm{M}}^{m} \Delta p}
$$

The efficiency $\eta_{\mathrm{M}}^{m}$ can be calculated using the torque $T_{a}$, which requires the installation of a transducer at the motor output. Then comes $\eta_{\mathrm{M}}^{m}=T_{a} / d_{\mathrm{M}} \Delta p$ or $\eta_{\mathrm{M}}^{m} \Delta p=T_{a} / d_{\mathrm{M}}$, where $d_{\mathrm{M}}$ is the current displacement (in contrast to the future value $d_{M}^{\prime}$ isolated on the left). In view of this, one can rewrite (26) as a ratio between future and present displacements:

$$
\frac{d_{\mathrm{M}}^{\prime}}{d_{\mathrm{M}}}=\frac{T_{e}+B_{a} \omega_{a}-J_{a} \kappa_{\mathrm{M}}\left(\omega_{a}-\omega_{a}^{*}\right)}{T_{a}}
$$

\subsubsection{Calculation of $\omega_{i}$}

Let $\omega_{i}^{k}=\omega_{i}\left(t_{k}\right)$ be the rotation of the field at instant $t_{k}$ of step $k$. Let $\omega_{i}^{*}$ be the steady state value (cf. the algorithm of Fig. 5). One can emulate feedback linearization by the exponential:

$$
\omega_{i}^{\prime}=\omega_{i}^{*}+\left(\omega_{i}^{k}-\omega_{i}^{*}\right) \exp \left[-\kappa_{i}\left(t-t_{k}\right)\right]
$$

While both the input and the loading conditions do not change, $\omega_{i}^{*}$ remains constant and the field rotation varies smoothly: $\omega_{i}^{\prime} \rightarrow \omega_{i}^{*}$. When the load or the wind power changes at a later time, the algorithm recalculates $\omega_{i}^{*}$ and the process is repeated. The time constant is given by: $\tau_{i}=1 / \kappa_{i}$.

\subsubsection{Calculation of $\omega_{i}^{*}$ and $s^{*}$}

Fitzgerald, Kingsley and Umans [17, p. 361] model the electromagnetic torque according to the phase voltage applied and the Thèvenin equivalent parameters of the induction motor:

$$
T_{e}=\frac{\mathrm{pp}}{\omega_{i}^{\text {ele }}} \frac{q V_{1 \mathrm{eq}}^{2} R_{2} / s}{\left(R_{1 \mathrm{eq}}+R_{2} / s\right)^{2}+\left(X_{1 \mathrm{eq}}+X_{2}\right)^{2}}
$$


where $q$ is the number of phases, indices 1 and 2 refer to the armature and the rotor, and the other parameters are given by the transformations:

$$
\begin{aligned}
V_{\text {1eq }} & =\left|\frac{V}{\sqrt{3}} \frac{\jmath X_{m}}{R_{1}+\jmath\left(X_{1}+X_{m}\right)}\right| \\
Z_{1 \text { eq }} & =\frac{\jmath X_{m}\left(R_{1}+\jmath X_{1}\right)}{R_{1}+\jmath\left(X_{1}+X_{m}\right)} \\
R_{1 \text { eq }} & =\operatorname{Re}\left(Z_{1 \text { eq }}\right) \\
X_{1 \text { eq }} & =\operatorname{Im}\left(Z_{1 \text { eq }}\right)
\end{aligned}
$$

The motor mechanical power is the product of the torque by the rotation $\omega_{i}$ and by $(1-s)$ :

$$
P=\frac{(1-s) q V_{1 \mathrm{eq}}^{2} R_{2} / s}{\left(R_{1 \mathrm{eq}}+R_{2} / s\right)^{2}+\left(X_{1 \mathrm{eq}}+X_{2}\right)^{2}}
$$

The solution to this quadratic equation, for $s$, is the set of roots $\mathbf{s}=\{(a \pm b) / c\}$, where

$$
\begin{aligned}
& a=q V_{1 \mathrm{eq}}^{2}-2 P R_{1 \text { eq }} \\
& b=\sqrt{\left(q V_{1 \mathrm{eq}}^{2}\right)^{2}-4 P\left[P\left(X_{1 \mathrm{eq}}+X_{2}\right)^{2}+q V_{\text {leq }}^{2}\left(R_{1 \mathrm{eq}}+R_{2}\right)\right]} \\
& c=2\left\{P\left[R_{1 \mathrm{eq}}^{2}+\left(X_{1 \mathrm{eq}}+X_{2}\right)^{2}\right] / R_{2}+q V_{\text {leq }}^{2}\right\}
\end{aligned}
$$

The root to choose here is the one with the lowest absolute value. In general, given two real numbers $x$ and $y$, this is calculated by:

$$
\text { least_abs }(x, y)=\frac{x+y}{2}-\frac{|x-y|}{2} \cdot \frac{|x+y|}{x+y}
$$

Applied to the slip, it results in:

$$
\begin{aligned}
s^{*} & =\frac{a+b+a-b}{2 c}-\left|\frac{a+b-a+b}{2 c}\right| \cdot \frac{|a+b+a-b| /|c|}{(a+b+a-b) / c} \\
& =\frac{a}{c}-\left|\frac{b}{c}\right| \cdot \frac{|2 a|}{2 a} \cdot \frac{c}{|c|}
\end{aligned}
$$

Once $|a| / a=\rfloor a\left\lceil, b \geqslant 0\right.$ and $|c|^{2}=c^{2}$, it follows that

$$
s^{*}=\frac{a-\rfloor a\lceil b}{c}
$$

As the equivalent impedances depend on the frequency, the roots must be calculated starting with $s=0$ and repeating the iteration up to $s \rightarrow s^{*}$ with negligible error. From the EFR reactance measurements obtained in the laboratory [18] for a particular frequency $(60 \mathrm{~Hz})$, it is possible to extrapolate to other frequencies by calculating, for a given $\omega_{i}^{\text {ele }}$,

$$
\left[\begin{array}{l}
X_{1} \\
X_{2} \\
X_{m}
\end{array}\right]=\frac{\omega_{i}^{\text {ele }}}{\omega_{i 0}^{\text {ele }}}\left[\begin{array}{l}
X_{1} \\
X_{2} \\
X_{m}
\end{array}\right]_{0}
$$

where the zero indicates measurements relative to the original experiment $(60 \mathrm{~Hz})$. Saturation effects are being neglected with this assumption. 
The mechanical power balance for the machine is: $P_{a}+P=P_{r}+\sum B \omega^{2}$, where $P$ is the inverter power contribution, (34). The S L IP algorithm (Fig. 5) proposes an iterative sequence that obtains $s^{*}$ and $\omega_{i}^{*}$.

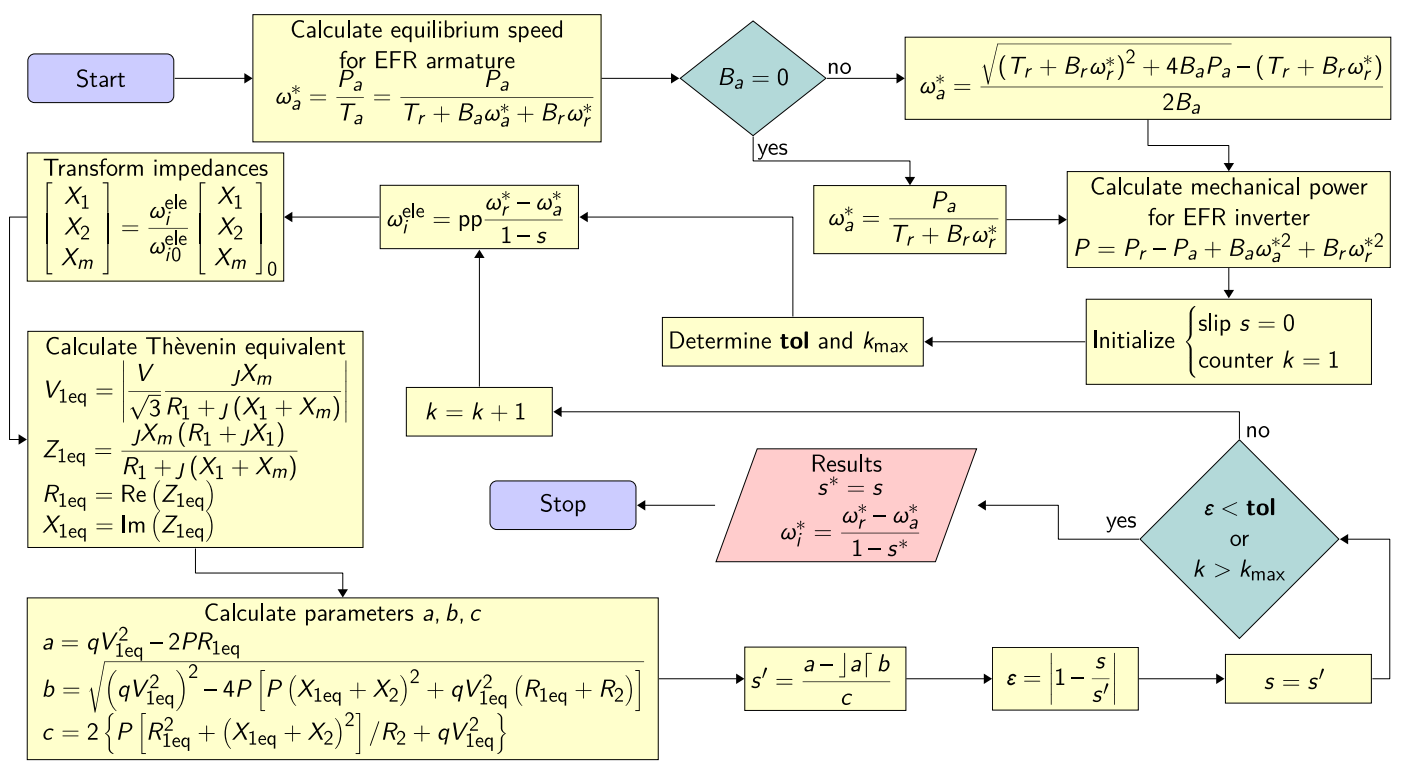

Figure 5. SLIP algorithm: calculation of the steady-state slip for the EFR when operating between powers $P_{a}$ and $P_{r}$

\section{Design Parameters}

IEC 61400-2 Standard [19], which deals with the design of small wind turbines, defines the nominal wind speed as the one associated with the maximum power, the speed being given by $v_{\text {nom }}=1.4 \bar{V}_{a}$, where $\bar{V}_{a}$ is the annual average wind speed. For this project, $\bar{V}_{a}=7 \mathrm{~m} / \mathrm{s}$. In the VPVS approach (variable pitch, variable speed), the power regulation acts in two different ways, depending on the wind speed (cf. regions I and II of the graph of Fig. 6). For large systems, depending on the interaction between pitch and stall controls, the power curve may have more regions, such as the example of a 1.5 MW turbine operating at $17 \mathrm{rpm}$, mentioned by Burton [15] (red line in the graph).

This work foresees (as will be seen ahead) the turbine operation with a rotation 8 times greater than that of the mentioned example, with 300 times less load — which motivates adopting the simplest strategy. (1) In the range $\left[v_{\text {cut-in }}, v_{\text {nom }}\right]$, the pitch control will adjust the blades to get maximum $C_{P}$. This strategy is known as Maximum Power Point Tracking (MPPT) [1,9]. (2) In the range $\left[v_{\text {nom, }}, v_{\text {cut-out }}\right]$ the operation is at full load. The power is limited to $P_{\text {nom }}$ by pitch and stall controls, with decreasing

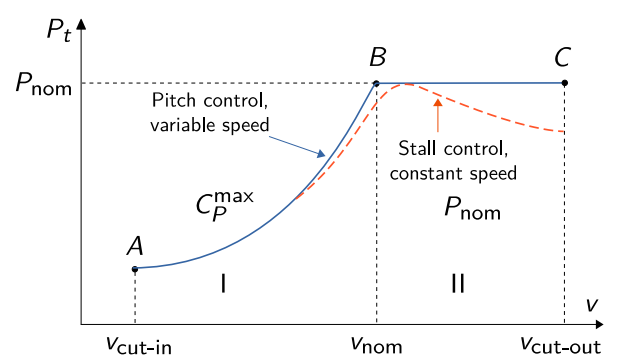

Figure 6. Power regulation schemes for wind turbines. Adapted from [15, p. 350] and [9, p. 47] 
rotations and increasing angles of attack [1]. The power coefficient is updated according to the restriction of (11), that is, $\frac{1}{2} \rho A C_{P}^{\max }\left(u_{\infty}^{\text {nom }}\right)^{3}=\frac{1}{2} \rho A C_{P} u_{\infty}^{3}$. This gives:

$$
\frac{C_{P}}{C_{P}^{\max }}=\left(\frac{u_{\infty}^{\mathrm{nom}}}{u_{\infty}}\right)^{3}
$$

Once calculated $C_{P}, \lambda$ (and $\omega_{t}$ ) can be found in the $C_{P}(\lambda)$ curve. Since the pitch control for MPPT employs more advanced tools than the ones used here [20-22], this work will adopt a constant power coefficient equal to $C_{P}^{\max }$ across region I, and the cubic relation (42) in region II.

The EFR design parameters were obtained from Pinheiro et al. [18] (cf Table 1). In order to satisfy a load of $5 \mathrm{~kW}$ at a wind speed of $7 \mathrm{~m} / \mathrm{s}$ and an armature power (design chosen) of $4 \mathrm{~kW}$, the SLIP algorithm was applied to these numbers, resulting in the set of values in the second column of Table 4 .

Table 1. Physical system constants [18]

\begin{tabular}{rlrl}
\hline \multicolumn{2}{c}{ Mechanical Quantities } & \multicolumn{2}{c}{ Electrical Quantities } \\
\hline$J_{a}\left(\mathrm{~kg} \cdot \mathrm{m}^{2}\right)$ & $0.0664084^{a}$ & $R_{1}(\Omega)$ & 0.66209 \\
$J_{r}\left(\mathrm{~kg} \cdot \mathrm{m}^{2}\right)$ & $0.501953^{b}$ & $R_{2}(\Omega)$ & 0.609071 \\
$\bar{V}_{a}(\mathrm{~m} / \mathrm{s})$ & 7 & $R_{m}(\Omega)$ & 108.28112 \\
$P_{r}(\mathrm{~kW})$ & 5 & $X_{1}^{0}(\Omega)$ & 0.7096819 \\
$B_{a}\left(\mathrm{~W} \cdot \mathrm{s}^{2} / \mathrm{rad}^{2}\right)$ & 0.003445 & $X_{2}^{0}(\Omega)$ & 0.7096819 \\
$B_{r}\left(\mathrm{~W} \cdot \mathrm{s}^{2} / \mathrm{rad}^{2}\right)$ & 0.00028589 & $X_{m}^{0}(\Omega)$ & 22.263793 \\
$\lambda_{d}$ & 7.5 & $\operatorname{pp}_{\mathrm{REF}}$ & $3^{c}$ \\
& & $\mathrm{pp}_{\mathrm{G}}$ & $3^{d}$ \\
& & $q$ & 3 \\
& & $V(\mathrm{~V})$ & 220 \\
\hline
\end{tabular}

${ }^{a}$ Includes mass moment of inertia of the hydraulic motor equal to $0.061 \mathrm{~kg} \cdot \mathrm{m}^{2}$ (cf. Table 3 ).

${ }^{b}$ Includes (estimated) mass moment of inertia of the generator equal to $0.5 \mathrm{~kg} \cdot \mathrm{m}^{2}$.

${ }_{c, d}$ Design decisions for this study.

From the energy flow relationships, (1)-(5), one can calculate the power of the hydraulic circuit elements, starting with the motor. (1) Assuming $\eta_{\mathrm{M}}^{v}=\eta_{\mathrm{M}}^{m}=0.95$, it follows that $P_{\mathrm{M}}^{\mathrm{in}}=4.43 \mathrm{~kW}$, the hydraulic power provided by the pump, (2). The pump driving power is the turbine wind power, (1). Assigning to the pump the same hydraulic and mechanical efficiencies of the motor gives $P_{t}=4.91 \mathrm{~kW}$. (2) The blade radius comes from (11), giving $R=\sqrt{2 P_{t} / C_{P} \rho \pi u_{\infty}^{3}}$. From adopting the value of 0.5 for the power coefficient outcomes a blade radius of $3.9 \mathrm{~m}$. (3) The flow rate is given by: $Q=P_{h} / \Delta p=$ $2.22 \times 10^{-4} \mathrm{~m}^{3} / \mathrm{s}=13.3 \mathrm{~L} / \mathrm{min}$, and the pump displacement comes from (6):

$$
d_{\mathrm{P}}=\frac{Q_{\mathrm{P}}}{\eta_{\mathrm{P}}^{v} \omega_{t}}=\frac{13.3 \times 10^{3} \mathrm{~mL} / \mathrm{min}}{0.95 \times \omega_{t} \mathrm{rpm}}=\frac{14 \times 10^{3}}{\omega_{t}} \mathrm{~mL} / \mathrm{rev}
$$

Since $\omega_{t}=\lambda u_{\infty} / R=13.43 \mathrm{rad} / \mathrm{s}=128.22 \mathrm{rpm}$, it follows that $d_{\mathrm{P}}=109.2 \mathrm{~mL} / \mathrm{rev}$. This result is a mere reference, as it will be necessary to search for real pumps that have a displacement close to that value. For example, the Bosch Rexroth AA2FO NG 107 axial pump has its $d_{\mathrm{P}}=106.7 \mathrm{~mL} / \mathrm{rev}$ [23]. With the adoption of this model, it is necessary to review the calculations (cf. Table 2).

(5) The power contribution of the inverter is given by $P_{i}^{*}=T_{e}^{*} \omega_{i}^{*}$, resulting in $1.05 \mathrm{~kW}$. Slip losses amount to $s^{*} P_{i}^{*}=15.6 \mathrm{~W}$. Friction losses, given by $B_{a} \omega_{a}^{* 2}+B_{r} \omega_{r}^{* 2}$, add up to $38.7 \mathrm{~W}$. The motor displacement is given by (7), resulting in $13 \mathrm{~mL} / \mathrm{rev}$. The ratio $d_{\mathrm{P}} / d_{\mathrm{M}}$, by (9), is 8.2 .

Since the turbine power is supposed to be the main energy source of the system, the quotient $P_{a} /\left[P_{a}+(1-s) P_{i}\right]$ must be high. This implies $P_{a} \gg P_{i}$ and $\omega_{a} \gg \omega_{i}$. Therefore, the turbine power 
Table 2. Revised pump requirements

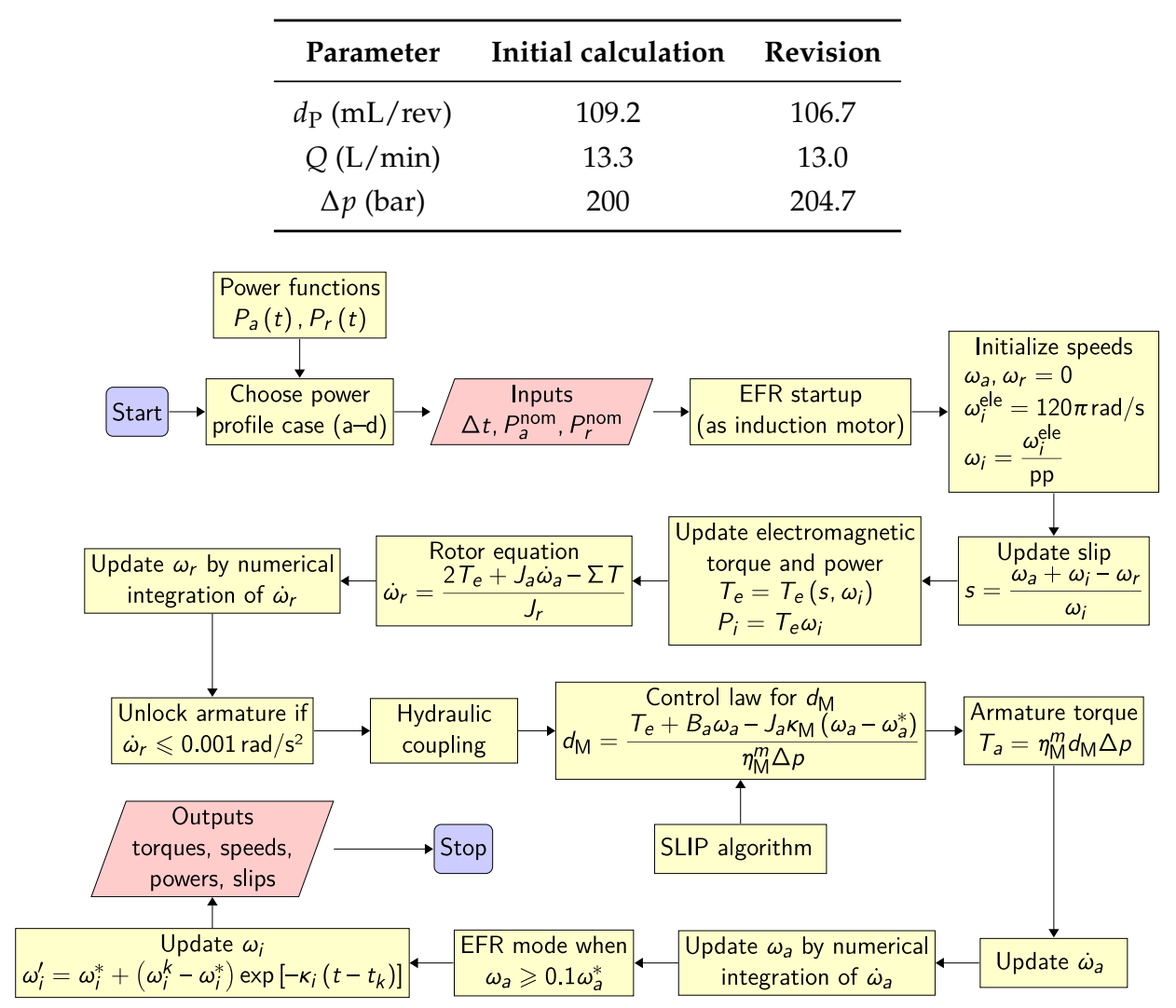

Figure 7. An outline of the simulation (no loops shown)

will be closer to the load than to the inverter power, and the armature rotation will be closer to the synchronous generator speed than to the field speed. The motor must then deliver a rotation as high as possible to the armature. However, if the wind speed is low, that may get less than desired, which suggests adopting a low synchronous rotation. Therefore, this project chooses a generator with three pairs of poles, which results in $\omega_{r}^{*}=1200 \mathrm{rpm}$. The parameters of the pump and the motor chosen as basis for the calculations are listed in Table 3.

Table 3. Constructive characteristics of the pump and motor used as an example for the simulation of the EFR system $[23,24]$

\begin{tabular}{lcccc}
\hline Component & $\begin{array}{c}d \\
(\mathrm{~mL} / \mathrm{rev})\end{array}$ & $\begin{array}{c}\omega_{t}^{\max } \\
(\mathrm{rpm})\end{array}$ & $\begin{array}{c}J \\
\left(\mathrm{~kg} \cdot \mathrm{m}^{2}\right)\end{array}$ & $\begin{array}{c}\Delta p_{\text {nom }} \\
(\mathrm{bar})\end{array}$ \\
\hline $\begin{array}{l}\text { Bosch Rexroth } \\
\text { AA2FO Axial }\end{array}$ & 106.7 & 1600 & 0.0116 & 400 \\
$\begin{array}{l}\text { Pump } \\
\text { Bosch Rexroth }\end{array}$ & & & & \\
$\begin{array}{l}\text { AEVM250 Axial } \\
\text { Motor }\end{array}$ & $0-250$ & 2700 & 0.061 & 350 \\
\hline
\end{tabular}

\section{Materials and Methods}

A Scilab program (version 6.0.2 64-bit) has been written to simulate the system response to certain load profiles in a given range of wind speeds. A brief outline of the calculation steps is shown on Fig. 7. Combinations of fixed or variable load and fixed or variable wind power were studied (Fig. 8). Cases A-C deal with pre-stipulated power levels; case D shows the load profile of case B and a random 
variation for $P_{a}$. The quantities will be presented in a normalized form (p.u.), where the measurement base of each quantity $x$ is its stationary state value $x^{*}$.

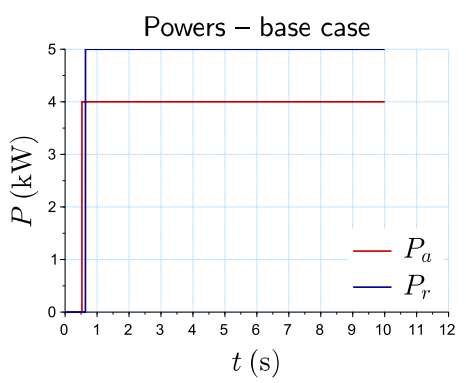

(a) Constant $P_{a}$ and $P_{r}$

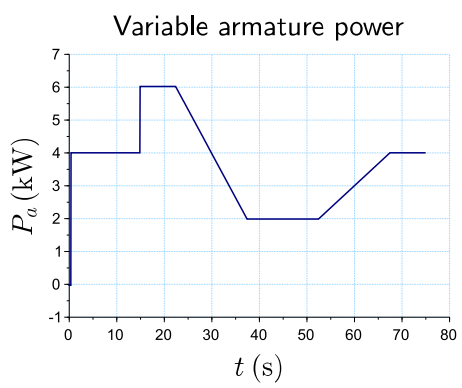

(c) Variable $P_{a}$

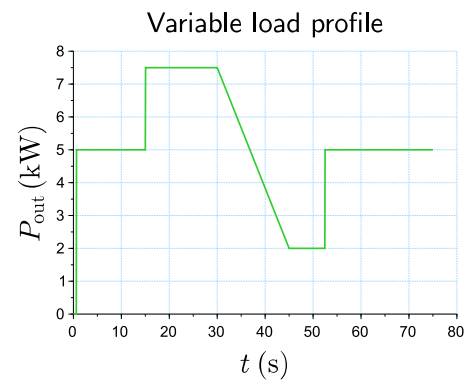

(b) Variable $P_{r}$

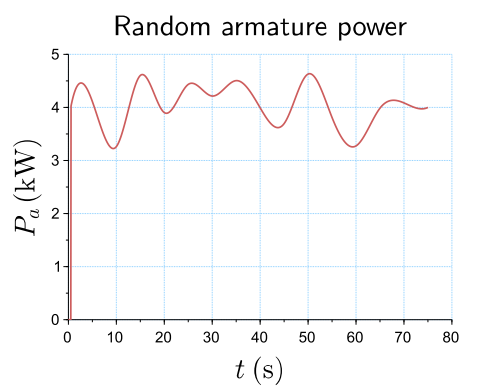

(d) Random $P_{a}$ with $P_{r}$ from case B

Figure 8. Power profiles: case studies

The EFR start follows this order: (1) Start as a conventional motor (armature locked); (2) Rotor stabilization; (3) Armature release; (4) Hydraulic system coupling and armature speed control; and (5) Field speed control. The rotor will be accelerated according to a balance of electromagnetic, load and friction torques. The load will be introduced in an instant $t_{0}$ when the rotor movement is sufficiently developed. The criterion adopted here is the maximum torque, when the slip values $s_{\operatorname{maxT}}=R_{2} / \sqrt{R_{1, \text { eq }}^{2}+\left(X_{1, \text { eq }}+X_{2}\right)^{2}}$ [17]. This will bring about maximum torque difference and maximum initial acceleration. Steady state will be considered achieved when $\dot{\omega}_{r}=0.001 \mathrm{rad} / \mathrm{s}^{2}$.

The armature is then unlocked. The objective here is to accelerate it up to the speed $\omega_{a}^{*}$ calculated with the SLIP algorithm. In order for the acceleration to take place in minimum time, it is necessary to apply a maximum hydraulic torque that overcomes the electromagnetic and frictional torques. To keep the operation smooth (mathematically and physically speaking), the torque decreases progressively, from the stabilized value of the previous phase to a new $T_{e}$ according to the slip variation. A power transient is expected. In fact, there was a peak almost $40 \%$ higher than the first one (start). This step is a quick transition to the full EFR regime, so it was arbitrated that this will occur when $\omega_{r}=0.1 \omega_{r}^{*}$, and then $\omega_{i}$ will be modified in exponential variation, according to (28).

Two critical situations can appear: when $\omega_{i} \rightarrow 0$ and when $s \rightarrow 0$. These are cases in which there is no electromagnetic torque. In this regard, the expedient adopted was, for the first case, to impose $\left|\omega_{i}\right| \geqslant 1 \mathrm{rad} / \mathrm{s}$, and, for the second, to add or remove a small fraction of $P_{a}$ when $\left|s^{*}\right|<0.001$ to increase the difference $\left|P_{r}-P_{a}\right|$. Physically, this corresponds to the use of some energy dissipating element or a change in the load profile. Naturally, numerical instabilities will arise in the vicinity of the critical values, characterizing prohibited zones. To treat the problem, a brake system can be introduced in the EFR/generator interconnection, with a control loop that will prevent the slip from falling into the instability places.

The relative error produced had an order of magnitude of $10^{-6}$ for a time step $h=1 / 500 \mathrm{~s}$ (value adopted in case A). For the other cases, it was necessary to have an $h=1 / 4000 \mathrm{~s}$, due to the stiffness of this problem: when the coupling occurs, the armature undergoes a strong acceleration, which causes a rapid increase in slip. So, the step needs to be short in that region. Table 4 summarizes the numbers. 
Table 4. Simulation results and relative errors for the four cases

\begin{tabular}{|c|c|c|c|c|c|}
\hline Quantity & Value & Case A & Case в & Case C & Case $\mathrm{D}$ \\
\hline$s^{*}$ & 0.01482 & $4 e-4$ & $1 e-9$ & $5 e-3$ & $4 e-1$ \\
\hline$\omega_{r}^{*}(\mathrm{rpm})$ & 1200.0 & $6 e-6$ & $2 e-11$ & $2 e-5$ & $3 e-4$ \\
\hline$\omega_{a}^{*}(\mathrm{rpm})$ & 950.9 & $8 \mathrm{e}-05$ & $2 e-10$ & $2 e-5$ & $9 e-2$ \\
\hline$\omega_{i}^{*}(\mathrm{rpm})$ & 252.8 & $3 e-04$ & $8 e-10$ & $7 e-5$ & $3 e-1$ \\
\hline$P_{a}^{*}, P_{i}^{*}, P_{r}^{*}(\mathrm{~kW})$ & \multicolumn{5}{|c|}{$4,1.05,5$} \\
\hline & & 1 & 1 & 1 & 1 \\
\hline$h(s)$ & & $\overline{500}$ & $\overline{4000}$ & $\overline{4000}$ & $\overline{4000}$ \\
\hline$\kappa$ parameters & \multicolumn{5}{|c|}{$\kappa_{i}=1, \kappa_{\mathrm{M}}=1$} \\
\hline$\Delta t(\mathrm{~s})$ & & 10 & 75 & 75 & 75 \\
\hline
\end{tabular}

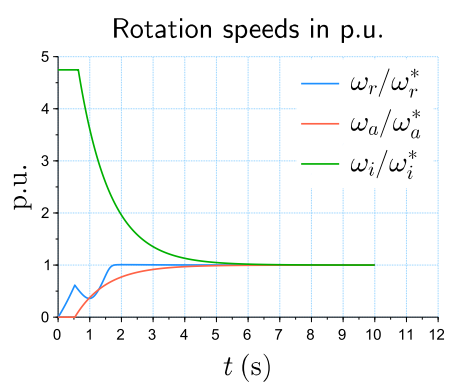

(a) speeds

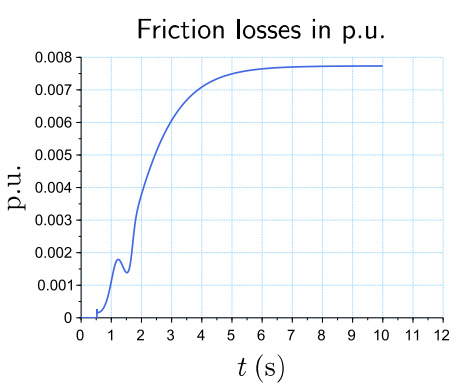

(d) friction

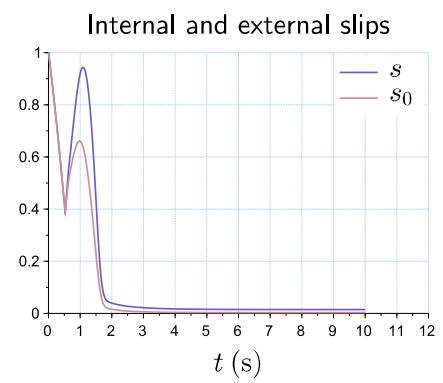

(b) slips

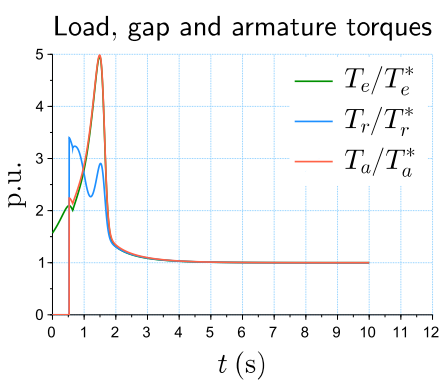

(e) torque balance

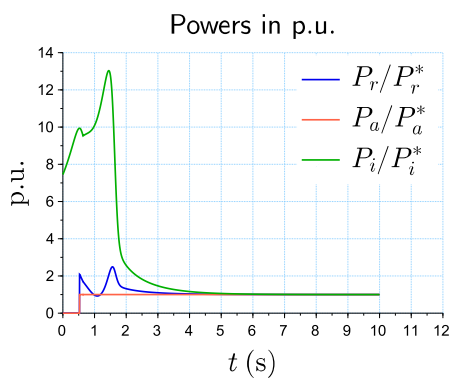

(c) powers

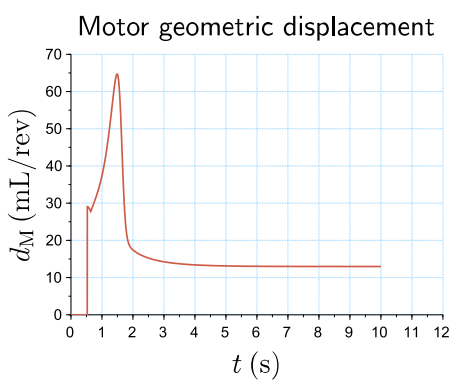

(f) control of $d_{\mathrm{M}}$

Figure 9. EFR operation: case A

\section{Results}

\subsection{Constant Turbine Wind Power and Load (Fig. 9)}

The start $(0-0.53 \mathrm{~s})$ is the same as a conventional motor, with $\omega_{i}=1200 \mathrm{rpm}$. The rotor is accelerated to an equilibrium place $(733 \mathrm{rpm})$ which is 61 percent $(0.61 \mathrm{p} . \mathrm{u}$.) of the final speed. In the steady state, $\omega_{i}^{*}=252.8 \mathrm{rpm}$, so $\omega_{i}$ should decrease and $\omega_{r}$ increase. The armature will be unlocked at the end of phase 1 and $\omega_{a}$ will reach $951 \mathrm{rpm}$. The rotor rotation drops slightly because the decrease of $\omega_{i}$ is greater than the increase of $\omega_{a}$ and also because of the growth of $s$. This will bring about a high power transient. Two peaks must occur: the first, related to the induction motor start, and a second one as an effect of the control over $\omega_{a}$. As the control performs the adjustments of $\omega_{a}$ and $\omega_{i}$, the slip falls again and the speeds converge to 1 p.u. Torques follow transients, both in power and slip. The curves tend to coincide at equilibrium, for the friction is negligible, and the motor displacement grows rapidly during the coupling, but converges to $d_{\mathrm{M}}^{*}=13 \mathrm{~mL} / \mathrm{rev}$ faster than as predicted by the $\kappa_{\mathrm{M}}$ constant. 


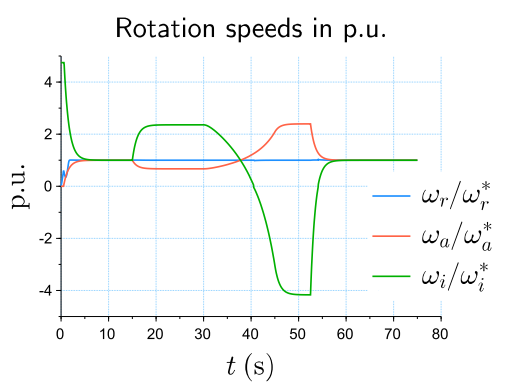

(a) speeds

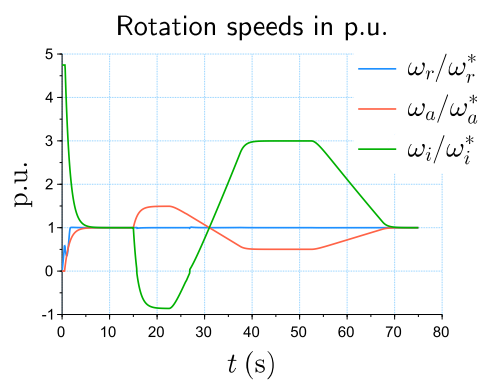

(a) speeds

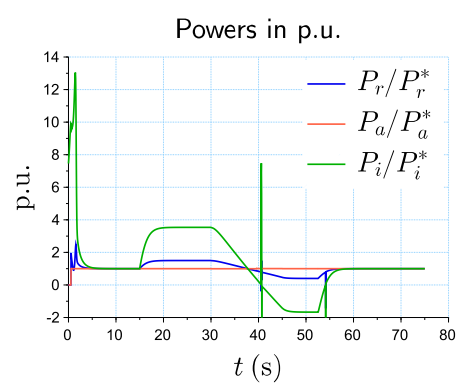

(b) powers

Figure 10. EFR operation: case $B$

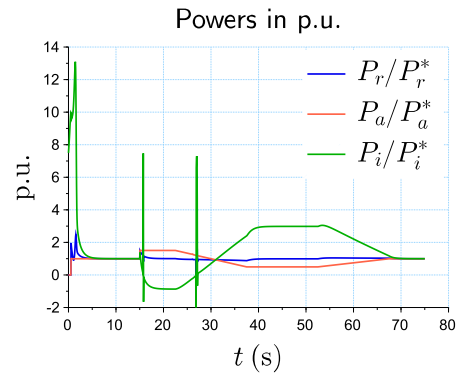

(b) powers

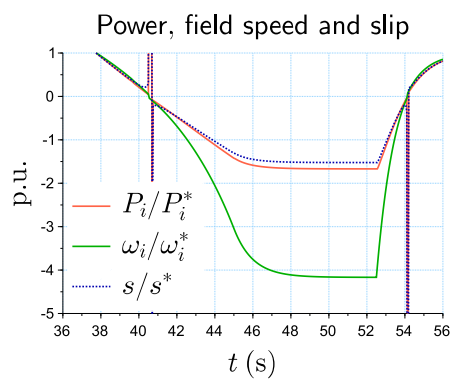

(c) regeneration

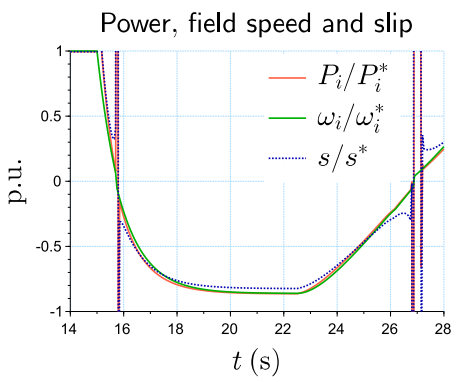

(c) regeneration

Figure 11. EFR operation: case $C$

\subsection{Constant Turbine Power and Variable Load (Fig. 10)}

The range of variation chosen for the load causes the response of the inverter in a range of powers that vary from positive contribution (adding power to the system) to negative (absorbing power to the battery). In the step-up ascent ( $15 \mathrm{~s})$, the control slows down the armature and accelerates the field. Shortly after $30 \mathrm{~s}$ the ramp descent begins and the opposite happens. The field rotation varies between 2.5 p.u. until it exceeds -4 p.u., inevitably changing its sign. The critical areas that occur are highlighted, first around $40.5 \mathrm{~s}$ and then near $54 \mathrm{~s}$. However, it is verified that the negative region of the electromagnetic power coincides with that of the negative field rotation and that of the negative internal slip. This indicates that the inverter draws turbine power in this interval, i.e., regeneration occurs (Fig. 10c). ${ }^{4}$ The slip decreases to -1.5 p.u., and the field rotation decreases to a little less than -4 p.u. until the equilibrium is interrupted by the next step-up ( $52.5 \mathrm{~s})$, enough shock to make the rotations and the slip return quickly to 1 p.u. The torque is always positive, once $\rfloor \omega_{i}\lceil=\rfloor P_{i}\lceil$.

\subsection{Variable Turbine Power and Constant Load (Fig. 11)}

The rotation of the field tends to decrease in the first step (15s), when the control will accelerate the armature and decelerate the field - the latter until close to -1 p.u., when it stabilizes until the beginning of the ramp (23s). Then $\omega_{i}$ passes from negative to positive close to $27 \mathrm{~s}$. Regeneration occurs in the interval that goes up to the second sign change of $\omega_{i}$. (Fig. 11c).

\subsection{Variable Turbine Power and Load (Fig. 12)}

Random changes in turbine rotation will cause variations in armature torque. As torque does not maintain linearity with slip, the response of the inverter may be proportionally greater or less than the $P_{t}$ variation, and key system components (armature and electromagnetic field) will undergo high accelerations. The response of the inverter, however, is consistent with hybridization: there is positive contribution when $s>0$ and negative (regeneration) otherwise. 


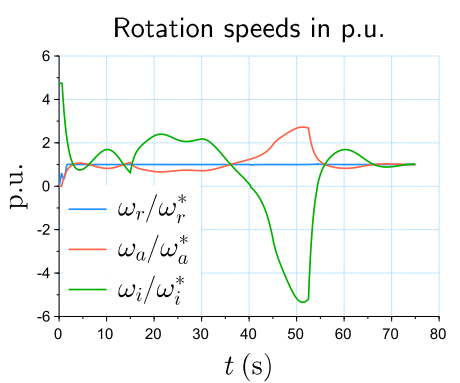

(a) speeds

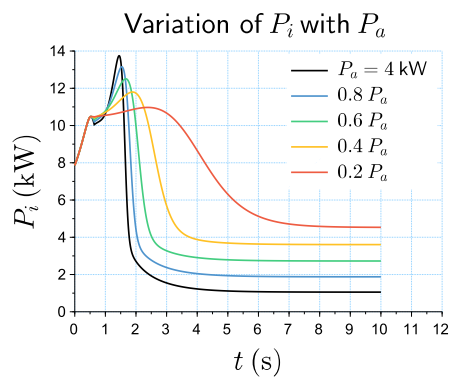

(a) lower slip peak

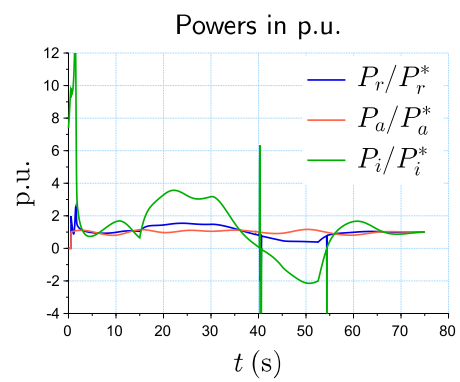

(b) powers

Figure 12. EFR operation: case D

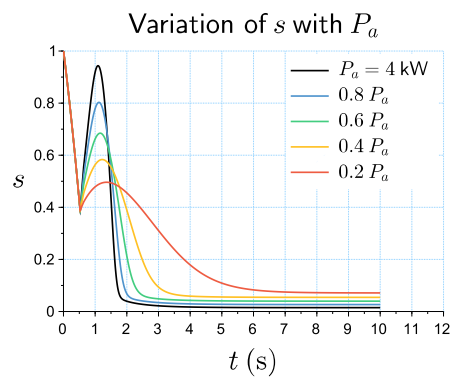

(b) rise of $s^{*}$

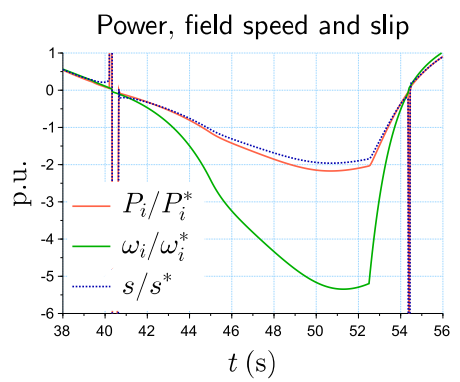

(c) regeneration

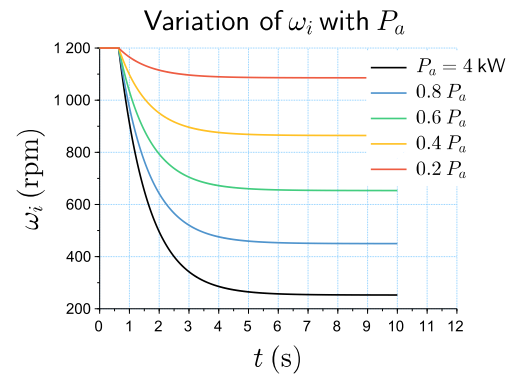

(c) approximation to the original $1200 \mathrm{rpm}$

Figure 13. EFR operation in fractions of $P_{a}$

\subsection{Studies on Input Power Variation (Figs. 13-14)}

An effective way to check the aptitude of the EFR for hybridization is to analyze the response of the system by varying the energy contribution of the inverter. The following graphs summarize a new batch of simulations made from inputs of $P_{a}$ in $0.2-1$ p.u. jumps, keeping the output of $5 \mathrm{~kW}$ constant (Figs 13a-13c). The inverter power curves show, especially at the lowest level $\left(0.2 P_{a}\right)$, that it takes longer for the control to reach equilibrium. The decrease in turbine power input leads to a decrease in the stiffness of the control law, and the power of the inverter converges more slowly $\left(5 \mathrm{~s}\right.$ with $1 P_{a}$ versus $8 \mathrm{~s}$ with $0.2 P_{a}$ ). This indicates that the control needs to raise the value of $\kappa_{i}$ and $\kappa_{\mathrm{M}}$ to stabilize the system at the same time as before. In addition, the rotation approaches the value of $\omega_{i}$ reached in the stabilization of the induction motor.

With $P_{a}=0.2$ p.u., the balance was delayed by less than $5 \mathrm{~s}$. If the value of $P_{a}$ is reduced 100 times, the time delay must be longer. The graph in Fig. 14a shows the evolution of the inverter power in that case. The stationary state was reached close to $180 \mathrm{~s}$. The novelty is an "unstable equilibrium" of $1.8 \mathrm{p} . \mathrm{u}$. around $5 \mathrm{~s}$ followed by a slight increase in power and then a slow decay until the stabilization at the level of $5.5 \mathrm{~kW}$. By way of comparison, the $P_{i}^{*}$ corresponding to $0.2 P_{a}$ is less than $4.5 \mathrm{~kW}$.

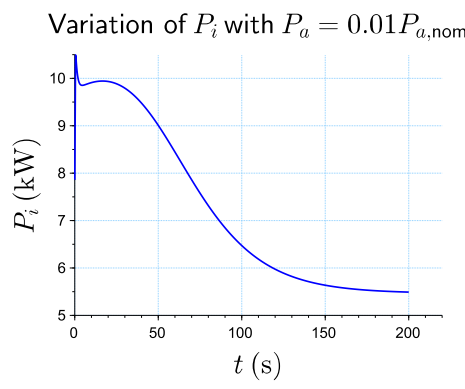

(a) power demand with low $P_{a}$

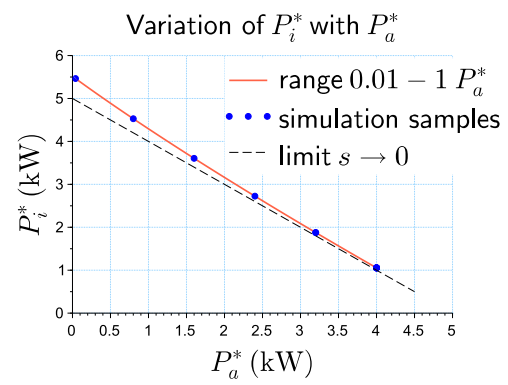

(b) powers

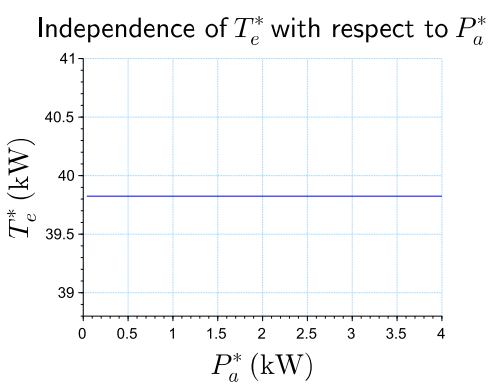

(c) torque

Figure 14. EFR equilibrium states for different fractions of armature power 
An overview of the equilibrium states is shown in Fig. 14b. The continuous range of values was calculated with the SLIP algorithm. The electromagnetic torque is kept constant over the whole power range (Fig. 14c). The linearity deviation is larger on the left, where $s$ grows more. This suggests that the performance of the EFR is superior in scenarios where it can share the energy input with the main source instead of supporting almost all the load.

\section{Conclusions}

An alternative for harnessing wind energy using a hydrostatic transmission system associated with the Electromagnetic Frequency Regulator has been introduced. A dynamic model was developed with emphasis on integration with the transmission, the wind turbine and a supplementary power source. The start-up and operation of the EFR were simulated under conditions of constant or variable load, and constant or variable turbine power. The results show that the system follows the pattern of the induction motor, complementing the turbine power to increase the load, or, in the opposite case, acting as an energy regenerator. It became evident that even with low turbine power, the system was able to supply the need for the load with slip lower than that of the induction machine under the same conditions (9.3\%); and, in the opposite situation, there was regeneration of the excess turbine power for the battery without compromising neither the load nor the rotor rotation.

The study has shown that using a hydrostatic transmission as a substitute for the speed multiplier in wind generators is a viable and efficient alternative. The association of a fixed displacement rotary pump with a variable displacement hydrostatic motor functionally replaces the gearbox, with the advantage of dynamic (controlled) change in gear ratio by employing a low inertia and low weight system.

The inclusion of the Electromagnetic Frequency Regulator (EFR) required an integrated modeling of the turbine/hydrostatic transmission/EFR/generator system, which led to an updated understanding of slip - from the conventional (static) definition to a generalized (dynamic) concept the internal slip, which includes the armature rotation. This adds important new features to the wind turbine: (1) The EFR has sufficient performance to ensure fast and efficient control of the generator shaft speed, keeping it constant, even if the wind speed is subject to variations; (2) Using the EFR, the electrical generation system delivers the sinusoidal voltage directly to the electrical grid or the load, without intermediation of any electronic devices; (3) Hence, the EFR provides an important innovation regarding the quality of energy in wind power generation systems, for it provides voltage free of harmonic distortions, as well as stable torque and power at the generator output; (4) There is a concrete possibility of hybridization, adding the wind energy with some other available form stored in battery (e.g., hydrogen cell).

It has been demonstrated that the EFR, working in a context where the power delivered by the turbine exceeds that drained by the generator, will operate in a braking region, where it will store energy into the battery through the inverter. This proves the regenerative capacity of the EFR, which can enable the generation of pseudo-hybrid projects, in which, if the turbine has more capacity than the generator load, it can be possible to store the excess energy captured at higher wind speeds, to use it when the turbine power is lower than the load.

Author Contributions: Conceptualization, A.P. and R.P.; methodology, A.P.; software, A.P.; validation, R.P. and G.M.; formal analysis, A.P.; investigation, A.P.; data curation, A.P.; writing-original draft preparation, A.P.; writing-review and editing, A.P.; supervision, R.P.. All authors have read and agreed to the published version of the manuscript.

Funding: This research received no external funding.

Conflicts of Interest: The authors declare no conflict of interest. 


\section{References}

1. Thumthae, C. Optimum Blade Profiles for a Variable-Speed Wind Turbine in Low Wind Area. Energy Procedia 2015, 75, 651 - 657. Clean, Efficient and Affordable Energy for a Sustainable Future: The 7th International Conference on Applied Energy (ICAE2015).

2. Mulugeta, B.; Gerawork, A. Aerodynamic design of horizontal axis wind turbine blades. FME Transaction 2017, 45, 647-660. doi:10.5937/fmet1704647M.

3. Okpue, A.S. Aerodynamic Analysis of Vertical and Horizontal Axis Wind turbine. Master's thesis, Michigan State University, 2011.

4. El-Okda, Y.M. Design methods of horizontal axis wind turbine rotor blades. International Journal of Industrial Electronics and Drives 2015, 2, 135. doi:10.1504/IJIED.2015.072789.

5. Hau, E. Wind Turbines, 2nd ed.; Springer, 2010.

6. Delft University of Technology. Hydraulic Wind Turbines, 2020.

7. Thomsen, K.E.; Dahlhaug, O.G.; Niss, M.O.K.; Haugset, S.K. Technological advances in hydraulic drive trains for wind turbines. Energy Procedia 2012, 24, 76-82.

8. Frøyd, L. Control System on a Wind Turbine: Evaluation of Control Strategies for a Wind Turbine with Hydraulic Drive Train by Means of Aeroelastic Analysis. Master's thesis, Norwegian University of Science and Technology, 2009.

9. Flesch, E.A. Projeto de transmissão hidrostática para aerogeradores de eixo horizontal. Master's thesis, Universidade Federal de Santa Catarina, 2012.

10. Silva, P.V.; Pinheiro, R.F.; Salazar, A.O.; Júnior, L.P.; Azevedo, C.C. A Proposal for a New Wind Turbine Topology Using an Electromagnetic Frequency Regulator. IEEE Latin America Transactions 2015, 13.

11. Silva, P.V.; Pinheiro, R.F.; Salazar, A.O.; Fernandes, J.D. Performance analysis of a new system for speed control in wind turbines. ICREPQ '15 - International Conference on Renewable Energies and Power Quality, 2015.

12. Silva, P.V.; Pinheiro, R.F.; Salazar, A.O.; dos Santos Júnior, L.P.; Fernandes, J.D. Um novo sistema para controle de velocidade em aerogeradores utilizando o Regulador Eletromagnético de Frequência. Eletrônica de Potência 2015, 20, 254-262.

13. da Costa, D.A. Projeto de um sistema híbrido de geração de energia elétrica conectado à rede, incluindo o Regulador Eletromagnético de Frequência (REF). Master's thesis, Universidade Federal do Rio Grande do Norte, 2016.

14. Ramos, T.; Júnior, M.F.M.; Pinheiro, R.; Medeiros, A. Slip Control of a Squirrel Cage Induction Generator Driven by an Electromagnetic Frequency Regulator to Achieve the Maximum Power Point Tracking. Energies 2019, 2100.

15. Burton, T.; Jenkins, N.; Sharpe, D.; Bossanyi, E. Wind Energy Handbook, second edition ed.; Wiley: West Sussex, UK, 2011.

16. Franklin, G.F.; Powell, J.D.; Emami-Naeini, A. Sistemas de controle para Engenharia, kindle ed.; Bookman: Porto Alegre, 2013.

17. Umans, S.D. Máquinas Elétricas de Fitzgerald e Kingsley, 7th ed.; Bookman, 2014.

18. Pinheiro, R.F.; de Souza, D.S.; de Carvalho Alves Pessoa, G.A.P.; de Freitas Nunes, E.A.; Souza, F.E.C. Medição dos parâmetros de circuito equivalente, através de ensaios de curto-circuito e circuito aberto. (Unpublished).

19. British Standards Institution. Wind Turbines: Part 2 - Design requirements for small wind turbines: BS EN 61400-2:2006, 2006.

20. Barakati, M.; Kazerani, M.; Aplevich, J. Maximum Power Tracking Control for a Wind Turbine System Including a Matrix Converter. IEEE Transactions on Energy Conversion 2009, 24, 705-713. doi:10.1109/TEC.2008.2005316.

21. Zhang, Y.; Zhang, L.; Liu, Y. Implementation of Maximum Power Point Tracking Based on Variable Speed Forecasting for Wind Energy Systems. Processes 2019, 7, 158. doi:10.3390/pr7030158.

22. Syahputra, R.; Soesanti, I. Performance Improvement for Small-Scale Wind Turbine System Based on Maximum Power Point Tracking Control. Energies 2019, 12, 3938. doi:10.3390/en12203938.

23. Bosch Rexroth. Axial piston fixed displacement pump AA2FO, 2018.

24. Bosch Rexroth. Axial piston variable motor AA6VM series 63 (Americas version). Borsch Rexroth AG, 2016. 
Sample Availability: Samples of EFR simulation software discussed here are available from the corresponding author. The data presented in this study are available on request from the authors. 